\title{
PERAN SERTA ORANG TUA DALAM SISTEM BUDAYA MUTU DI SEKOLAH DASAR PSKD MANDIRI
}

\author{
DWI RAHAYU*
}

\begin{abstract}
The objective of this research is to gain a deep understanding of the parents involvement in a quality culture system in PSKD MANDIRI Primary School. This research is a case study method. The validity of qualitative data obtained through the extention of time doing research and triangulation of data collection techniques and data sources in the field. The result show: Interpersonal communication in PSKD Mandiri Schools is the result of a good engagement between teachers and parents. Parents understand the procedures how to make a contact with teachers. Parents are also free to choose the communication channel that they desired. Schools encourage the use of technology in the communication between home - school. Several form of written communication have been considered including handbooks, newsletter, progress reports and home - school diaries. Guidelines have been also provided for the use of telephone contacts with parents and for the use of new technological option such as school website, e-mail, ans text messaging. Therefore, it is considered that making a range of strategies available to parents will lead to optional levels of parental involvement in school. However the range of strategies used by the school will mostly be dependent on teachers's knowledge of and skills for effectively implementing the various strategies. The wide range of activities is also used by school to bring about high levels of parental involvement.
\end{abstract}

\section{Keywords : Interpersonal Communication and Parents Participation}

\section{PENDAHULUAN}

Banyaknya sekolah baru bermunculan dan kompetisi antar sekolah yang semakin tajam, menuntut pihak SD PSKD Mandiri untuk mengadakan perbaikan.Yayasan Perkumpulan Mandiri berusaha mengadakan tindakan yang berbeda. Pembenahan diarahkan kepada peningkatan mutu. Mutu merupakan prasyarat yang harus dipenuhi.

SD PSKD Mandiri menyadari bahwa orang tua merupakan salah satu elemen penting dalam meningkatkan dan mengembangkan mutu organisasinya. Peranan orang tua tidak dapat diabaikan. Orang tua memiliki potensi yang besar yang dapat didayagunakan dalam mendukung budaya mutu. Orang tua dapat mengambil peran dalam memelihara, menumbuhkan, meningkatkan dan mengembangkan sekolah.

Pada Tahun 2007 manajemen SD PSKD Mandiri melakukan restrukturisasi sekolah. Berbagai upaya pembenahan diimplementasikan. Pembenahan itu termasuk pula dalam hal peran serta orang tua. Mengembangkan kemitraan antara sekolah dan orang tua bukanlah hal yang mudah. Tantangan tersebut juga menjadi kendala tersendiri bagi Sekolah PSKD Mandiri.

Menurut Direktur Penyelenggaraan Pendidikan SD PSKD Mandiri, ada dua alasan mengapa keterlibatan orang tua sangat penting: "There are two ways, first related to students academic. Study shows that when parents involve at school in the right way then students will achieve more academically. The second one is if parents engage more in school, it will improve costumer loyalthy. Costumer will stay longer. So both reasons will be very important for survival of the school. Alasan pertama, berhubungan dengan pencapaian kemampuan akademik siswa. Penelitian menyimpulkan bahwa ketika orang tua aktif

\footnotetext{
* Koordinator Training dan Mentoring Sekolah PSKD Mandiri
} 
berperan di sekolah dengan cara-cara yang tepat maka akan meningkatkan prestasi putra-putrinya. Alasan kedua, keterlibatan orang tua akan meningkatkan kesetiaan pelanggan. Melalui kesetiaan pelanggan maka pelanggan akan bertahan lebih lama. Kedua alasan tersebut sangat penting bagi keberlangsungan SD PSKD Mandiri.

SD PSKD Mandiri mengkaji ulang peranan orang tua dalam kegiatan dan program sekolah. Apa yang diimplementasikan SD PSKD Mandiri sejalan dengan pendapat Grant and Ray (2010:24) yang menyatakan bahwa "The most effective schools are now widely considered to be ones that encourage and support the involvement of parents and other family members in the education of their children." Sekolah-sekolah yang paling efektif saat ini sangat mendukung peran serta orang tua dan anggota keluarga lainnya dalam proses pendidikan putra-putri mereka.

Rencana strategis PSKD Mandiri tentang orang tua dan masyarakat dijabarkan dalam tiga aspek yaitu nilai dan budaya, pengajaran dan pembelajaran serta kepemimpinan dan lingkungan. Pada aspek nilai dan budaya (Values and Culture) adalah SD PSKD Mandiri menekankan pentingnya suatu komunikasi yang efektif antara orang tua/ masyarakat dengan sekolah. Komunikasi yang terjalin efektif ini menjadi nilai-nilai yang menjiwai seluruh warga sekolah. Dalam aspek pengajaran dan pembelajaran (Teaching and Learning) ditekankan pentingnya peran serta orang tua dalam proses pembelajaran putra-putrinya, termasuk membangun jejaringan dengan organisasi lain untuk mendukung program pembelajaran di sekolah. Sedangkan aspek kepemimpinan dan lingkungan (Leadership and Environment), orang tua diharapkan mendukung sekolah dengan menciptakan lingkungan yang baik bagi proses penyelenggaraan pendidikan bagi anak-anaknya.

Peran serta orang tua dalam sistem budaya mutu sudah seharusnya menjadi strategi penting. Dalam masyarakat global yang semakin kompetitif saat ini, peran aktif orang tua mampu mendorong kesuksesan siswa dan mempersiapkan karirnya di masa mendatang. Walaupun penelitian berulang kali mengkorelasikan keterlibatan orang tua dengan meningkatnya kesuksesan siswa namun strategi ini masih belum banyak diaktifkan sebagai bagian integral dari upaya pengembangan mutu sekolah.

Dengan demikian, setelah memperhatikan fenomena yang terjadi, peneliti tertarik untuk melihat, menggambarkan dan menganalisis peran serta orang tua dalam sistem budaya mutu yang ada di Sekolah Dasar PSKD Mandiri. Dengan demikian, judul yang sesuai untuk tesis ini adalah Peran Serta Orang Tua dalam Sistem Budaya Mutu di SD PSKD Mandiri.

\section{Budaya Mutu}

Goetsch dan Davis(2013:82) mengungkapkan tentang makna budaya mutu sebagai: "A quality culture is an organizational value system that result in an environment that is conductive to the establishment and continual improvement of quality. It consist of value, traditions, procedures, and expectation that promote quality. Budaya mutu adalah sistem nilai organisasi yang menghasilkan suatu lingkungan yang kondusif bagi pembentukan dan perbaikan mutu secara terus-menerus.

Budaya mutu terdiri dari filosofi, keyakinan, sikap, norma, nilai, tradisi, prosedur dan harapan untuk meningkatkan mutu. Watson M.A., dan Gryna, F.M. (2001:41) mengemukakan, "Quality culture is the pattern of habits, beliefs, and behaviour concerning quality". Sedangkan Hardjosoedarmo (2004:92) memaparkan budaya mutu adalah pola nilai-nilai, keyakinan dan harapan yang tertanam dan berkembang di kalangan anggota organisasi mengenai pekerjaannya untuk menghasilkan produk dan jasa yang bermutu. 
Budaya mutu adalah suatu nilai, keyakinan dan harapan bersama dalam suatu organisasi untuk menghasilkan produk atau jasa yang bermutu. Bila dikaitkan dengan organisasi sekolah, maka kebiasaan ini menumbuhkan perasaan dalam diri warga sekolah tentang bagaimana berperilaku yang seharusnya. Sistem budaya yang bermutu menjadi ruh dalam peningkatan dan pengembangan organisasi sekolah serta mampu memberikan pengalaman bagi tumbuh kembangnya sekolah.

\section{Peran Serta Orang Tua}

Posisi orang tua sebagai salah satu stake holder sekolah sangat besar dan penting peranannya dalam melakukan perubahan dan pembaharuan di sekolah. Dalam hal ini, Kudjo (2013:15) menyampaikan bahwa, "Partnerships between schools and other community organizations form a strong base for experiential learning and offer students opportunities to make connections that will be relevant to their future careers. Kerjasama antara sekolah dan orang tua serta organisasi kemasyarakatan akan membentuk pondasi yang kuat dalam pembelajaran aplikatif dan memberikan kesempatan kepada siswa untuk terhubung dengan masyarakat dan penting bagi pengembangan karirnya di masa mendatang.

Jeynes (2005:245) mengatakan bahwa, "Parental involvement is parental participation in the educational process and experiences of their children." Peran serta orang tua adalah partisipasi orang tua baik dalam proses pendidikan maupun pengalaman anak mereka. Sedangkan Hornby (2011:1) menyampaikan sebagai berikut "Parental involvement includes home based parental involvement such as listening to children, reading and supervision of homework as well as school based parental involvement such as attending parent education workshops and parent-teacher meeting. Peran serta orang tua adalah keterlibatan orang tua dalam membantu proses belajar anak di rumah seperti mendengarkan cerita, membacakan buku serta melakukan pengawasan PR sedangkan peran serta orang tua di sekolah antara lain menghadiri seminar pendidikan yang diselenggarakan oleh sekolah atau mengadakan pertemuan dengan guru.

Beberapa penelitian menyatakan bahwa peran serta orang tua berpengaruh terhadap keberhasilan akademik dan keterampilan sosial siswa. Di dalam buku Boal, "Changing the Context of Learning for a Better Education", Kudjo (2013:13) mengungkapkan "Research shows positive results in student achievement, attendance, health, and discipline when parents are partners in their children's education; and to build this partnership requires the three-pronged approach : families connecting to schools; schools connecting to families; and communities connecting to both schools and families Penelitian menunjukan hasil yang sangat positif dalam prestasi akademik, kehadiran, kesehatan serta kedisiplinan siswa ketika orang tua bekerjasama dengan sekolah dalam proses pendidikan anak-anak mereka. Dibutuhkan tiga pendekatan dalam mengembangkan kerjasama ini yaitu : pendekatan orang tua kepada sekolah; sekolah kepada orang tua; dan masyarakat kepada sekolah dan orang tua.

Ada beberapa faktor penting dalam mengembangkan peran serta orang tua, yaitu adanya komunikasi interpersonal yang efektif antara guru dan orang tua dan partisipasi orang tua.

\section{Komunikasi Interpersonal}

Dalam menciptakan peran serta orang tua yang efektif diperlukan kerjasama yang harmonis antara sekolah dan orang tua. Komunikasi adalah hal penting dalam mewujudkannya. Sebagaimana disampaikan oleh Eipstein (1995:701), "communication is the key to successful parent involvement". Komunikasi adalah kunci dalam keberhasilan 
peran serta orang tua. Dengan kata lain, komunikasi memiliki pengaruh yang besar terhadap kesuksesan peran serta orang tua.

Lebih lanjut Ramirez (2001:4) menyatakan, "both teachers and parents agree that communication is pivotal to foster and maintain a positive school-home partnership, but, the reality is that each feels that the other party is responsible for initiating communication". Guru dan orang tua percaya bahwa untuk memelihara kemitraan yang positif antara pihak sekolah dan orang tua diperlukan komunikasi yang baik. Namun guru dan orang tua perlu bersikap proaktif dalam menjalin komunikasi dan tidak saling menunggu.

Penggunaan teknologi sebagai bentuk komunikasi antara sekolah dan orang tua banyak pula digunakan di beberapa sekolah saat ini. Menurut Turnbull et all (2011:77), "it is considered that such as strategies have great potential for increasing effective parental involvement and along with other recent innovations, will become an integral part of school strategies for parental involvement in the future" Penemuan-penemuan teknologi terbaru, memiliki potensi yang besar dalam meningkatkan peran serta orang tua, dan merupakan strategi penting dalam pengembangan peran serta orang tua di masa depan.

\section{Partisipasi}

Newstrom(2007:182) mendefinisikan partisipasi adalah "the individual's mental and emotional involvement of people in group situations that encourages them to contribute to group goals and a share responsibility for them" Partisipasi adalah keterlibatan mental dan emosional orang-orang dalam suatu situasi yang mendorong mereka untuk berkontribusi agar mencapai tujuan kelompok/organisasi dan memiliki tanggung jawab masing-masing.

Partisipasi menurut Newstrom menitik beratkan pada keterlibatan mental, tetapi Robbins sebaliknya yaitu partisipasi merupakan istilah yang lebih terbatas dibandingkan dengan keterlibatan, sebab semua program partisipasi adalah bagian dalam keterlibatan. Robbins (2006:272) kemudian mendefinisikan keterlibatan dengan proses mendorong peningkatan komitmen bagi suksesnya organisasi.

Pierce (2002:361) menghubungkan partisipasi dengan tujuan yaitu partisipasi memberikan kontribusi akan pemahaman dan perasaan memiliki untuk mencapai tujuan organisasi kepada orang-orang yang terlibat dalam proses pencapaian tujuan.

Dari teori tersebut partisipasi penting dalam peningkatan mutu suatu organisasi. Dalam rangka mewujudkan visi dan misi sekolah sesuai dengan paradigma baru sekolah perlu memberdayakan orang tua dan masyarakat secara optimal. Sekolah memerlukan masukan dari orang tua dan dukungan dalam melaksanakan program sekolah.

\section{METODE}

Dalam penelitian ini, peneliti menggunakan pendekatan kualitatif dengan metode studi kasus dari Robert K. Yin (2009:66) dengan beberapa tahapan yaitu plan, design, prepare, collect, analysis, share. Latar penelitian ini dilakukan di Sekolah Dasar PSKD Mandiri. Adapun grand tour observation yang dilakukan selama 7 bulan, sejak Februari 2014. Sedangkan penelitian dilakukan mulai bulan Januari sampai Juni 2015.

\section{HASIL DAN PEMBAHASAN Komunikasi Interpersonal}

Berdasarkan data hasil wawancara, observasi dan dokumentasi, peneliti menemukan data terkait komunikasi interpersonal dan partisipasi. Salah satu aspek 
komunikasi interpersonal yang didapatkan melalui hasil wawancara adalah proses komunikasi interpersonal. Seluruh informan menganggap bahwa komunikasi interpersonal antara orang tua dan guru di SD PSKD Mandiri sangat penting. Sebagai orang yang berada dengan murid sepanjang hari, guru memegang peranan penting. Proses komunikasi interpersonal antara guru dan orang tua dalam sistem budaya mutu di SD PSKD Mandiri memiliki standar operasional yang telah ditetapkan. Prosesnya sendiri berjalan terbuka dan dukungan sekolah untuk proses tersebut cukup besar. Prosedur yang dilakukan tergantung kebutuhan.

Secara umum yang dibicarakan ketika komunikasi interpersonal antara orang tua dan guru berlangsung adalah hal-hal yang berhubungan dengan kemampuan akademik dan keterampilan sosial siswa. Kemampuan akademik adalah kemampuan siswa dalam mengikuti pelajaran meliputi ulangan harian, tes dan materi ajar sedangkan keterampilan sosial meliputi bagaimana sikap dan keseharian siswa di dalam kelas, hubungan dengan teman-temannya dan perkembangan karakter. Prosesnya sendiri ada yang bersifat spontan atau melalui perjanjian. Orang tua memahami aturan kapan sebaiknya pertemuan dengan guru berlangsung.

Sekolah memfasilitasi komunikasi interpersonal yang efektif dengan orang tua dengan menyediakan ruangan khusus bagi orang tua. Menurut para informan, indikator ukuran keberhasilan komunikasi interpersonal antara guru dan orang tua antara lain adalah anak senang datang ke sekolah, perkembangan akademik dan karakter siswa semakin baik, orang tua dan guru saling percaya dan loyal terhadap sekolah. Secara keseluruhan, komunikasi interpersonal antara guru dan orang tua telah menjadi bagian dari budaya mutu dalam penyelenggaraan pendidikan di SD PSKD Mandiri.

SD PSKD Mandiri mendorong penggunaan teknologi dalam berkomunikasi dengan orang tua yang merupakan bagian dalam sistem budaya mutu sekolah. Sekolah memperbaiki penampilan website lebih baik dan meminta masukan orang tua agar sesuai dengan keinginan para pelanggan. Tidak hanya informasi dan gambaran apa saja yang terjadi di dalam kelas, website juga memuat masukan, kritikan dan survey orang tua bagi perbaikan mutu sekolah. Penggunaan lain seperti e-mail, sms blast, wa, bbm, bahkan facebook sebagai bagian dalam mendekatkan hubungan rumah-sekolah yag efektif.

Di awal tahun, sekolah menyampaikan kepada orang tua tentang hak dan tanggung jawabnya dalam organisasi sekolah. Pihak sekolah, diwakili oleh kepala sekolah dan guru-guru menyampaikan informasi kepada orang tua melalui pertemuan yang dinamakan info session. Selain itu, orang tua mendapatkan handsbook, atau buku petunjuk aturan sekolah kebijakan bagi murid yang perlu diperhatikan oleh orang tua. Di dalamnya memuat aturan, petunjuk, standar operasional yang diterapkan oleh skolah. Orang tua dan guru cukup memahami standar operasional tersebut. Kendati demikian berdasarkan temuan di lapangan, SD PSKD Mandiri perlu memiliki buku petunjuk (handsbook) khusus bagi orang tua yang memiliki anak berkebutuhan khusus. Orang tua yang memiliki anak berkebutuhan khusus memerlukan buku petunjuk yang mungkin berbeda dengan orang tua pada umumnya. Hal ini dipertegas oleh pendapat Kroth (1985:214) bahwa "Parents of children with special education needs (SEN) appreciate having a handbook written especially for them." Orang tua yang memiliki anak berkebutuhan khusus selain mempunyai buku aturan sekolah secara umum, sebaiknya memiliki buku aturan khusus pula. Di dalam buku tersebut dapat memuat prosedur, kontak komunikasi bagi anak berkebutuhan khusus, laporan kepada orang tua dan sebagainya. SD PSKD Mandiri perlu mempertimbangkan penggunaan buku anak berkebutuhan khusus ini. 
Salah satu kendala di SD PSKD Mandiri dalam melakukan hubungan komunikasi interpersonal antara guru dan orang tua adalah sudut pandang orang tua yang merasa lebih memahami anaknya. Selain itu, orang tua merasa bahwa cara berkomunikasi guru ketika menyampaikan permasalahan terkadang kurang efektif sehingga menyebabkan orang tua menjadi defensif. Di satu sisi, terkadang guru merasa lebih mengetahui apa yang terjadi dengan anaknya. Hal ini tentu menjadi tantangan bagi proses komunikasi yang efektif. Kendala yang lain adalah kesibukan orang tua. Sebagian besar orang tua di SD PSKD Mandiri adalah profesional sehingga waktu menjadi kendala. Wacana bertemu yang telah disetujui menjadi tertunda karena faktor kesibukan. Adapula orang tua yang kurang memahami peranannya dalam pendidikan anak dan lebih menyerahkan sebagian tanggung jawabnya kepada asisten rumah tangga atau supir. Hal-hal tersebut tentu dapat menjadi kendala dalam membangun hubungan rumahsekolah yang efektif.

SD PSKD Mandiri menyadari bahwa agar dapat bekerjasama secara efektif dengan orang tua, guru perlu memiliki keterampilan komunikasi interpersonal yang baik. Temuan tersebut sejalan dengan konsep Hornby(2011:98) "In order to work effectively with parents, professionals such as teachers, psychologists, social workers, and counselors working in schools need to have good interpersonal communication skills." Agar dapat bekerjasama secara efektif dengan orang tua, profesional seperti guru, psikolog, pekerja sosial, konselor perlu memiliki keterampilan komunikasi interpersonal yang baik. Kendati demikian keterampilan komunikasi ini belum dirancang secara sistematis sebagai bagian dari program training guru di SD PSKD Mandiri. Sejauh ini pimpinan berusaha menghimbau agar guru melakukan pendekatan tersebut. Penekanan pada pelatihan yang diberikan kepada guru lebih kepada proses-belajar mengajar. Walaupun sekolah menyadari bahwa hubungan dengan orang tua penting namun pelatihan guru tentang teknik berkomunikasi dengan orang tua belum dianggap terlalu serius. Sesungguhnya guru senior atau pimpinan dapat bekerjasama memberikan pelatihan keterampilan ini. Melalui pemahaman dan keterampilan dasar dalam kegiatan mendengarkan, konseling dan kegiatan yang bersifat mengarahkan/asertif, guru di SD PSKD Mandiri diharapkan dapat lebih terampil dan efektif menjalin komunikasi dengan orang tua.

Upaya-upaya lain yang dilakukan oleh SD PSKD Mandiri dalam mengembangkan komunikasi yang efektif dengan orang tua antara lain: mempertahankan sistem komunikasi yang terbuka, peningkatan keterampilan komunikasi guru kepada orang tua, mengembangkan pemahaman peranan orang tua dalam pendidikan, mendorong terus keberadaan seorang koordinator orang tua sebagai wakil sekolah dalam menjembatani hubungan rumah - sekolah yang lebih harmonis, sistem pendataan perkembangan siswa yang lebih baik, serta dukungan pimpinan terhadap komunikasi interpersonal antara orang tua dan guru yang optimal. Sedangkan kondisi komunikasi interpersonal antara guru dan orang tua di SD PSKD Mandiri dirasakan positif.

\section{Partisipasi}

Selain komunikasi interpersonal, partisipasi merupakan hal yang penting dalam peran serta orang tua di sekolah. Dalam temuannya, peneliti mendapatkan data bahwa sekolah dan yayasan memandang peran serta orang tua sangat penting dalam sistem budaya mutu di SD PSKD Mandiri. Peranan orang tua tidak hanya di sekolah saja melainkan juga di rumah. Latar belakang pendidikan orang tua yang cukup baik, menunjang pemahaman tersebut. Kendati demikian pemahaman teori saja tidak cukup, diperlukan tindakan nyata seperti aktif berpartisipasi mendukung sekolah. Prosentasi kehadiran orang tua di sekolah perlu ditingkatkan. 
Strategi yang dilakukan oleh SD PSKD Mandiri untuk mendorong bakat dan kemampuan minat orang tua untuk berperan secara aktif antara lain dengan mengadakan mengaplikasikan Parents Engagement System, menunjuk tiga orang perwakilan orang tua hadir dalam rapat-rapat penting yayasan, memfasilitasi ruangan khusus bagi pertemuan orang tua, menyelenggarakan beragam seminar bagi orang tua dan dukungan pimpinan terhadap pengembangan peranan orang tua. SD PSKD Mandiri juga memiliki kebijakan tertulis yang memuat aspek-aspek peran serta orang tua serta menunjuk seorang koordinator peran serta orang tua. Kondisi ini sejalan dengan pendapat Newstrom(2007:182) yang mendefinisikan partisipasi adalah "the individual's mental and emotional involvement of people in group situations that encourages them to contribute to group goals and a share responsibility for them" Partisipasi adalah keterlibatan mental dan emosional orang-orang dalam suatu situasi yang mendorong mereka untuk berkontribusi agar mencapai tujuan kelompok/organisasi dan memiliki tanggung jawab masing-masing.

Koordinator peran serta orang tua yang berasala dari tim manajemen ini bertugas dalam mendukung aktifitas peran serta orang tua yang beragam sesuai dengan visi, misi serta nilai-nilai sekolah. Tugas pertama koordinator peran serta orang tua adalah melakukan audit peran serta orang tua di sekolah dan menyiapkan laporan untuk kepala sekolah dan yayasan untuk memfasilitasi pengembangan sistem yang komprehensif tentang peran serta orang tua di sekolah. Apa yang diterapkan oleh SD PSKD Mandiri ini didukung oleh pendapat Eipstein dan Salinas (2013:67) sebagai berikut, "What is needed in school is a comprehensive system of parental involvement that includes all key aspects. In order to achieve this, it is sugested that elementary schools need to have a parental involvement coordinator who is an experienced teacher or member of the school's senior management team." Yang diperlukan oleh sekolah adalah sebuah sistem peran serta orang tua yang komprihensif yang meliputi seluruh aspek. Dalam rangka mencapai tujuan tersebut, sangat disarankan bahwa sekolah dasar memliki seorang koordinator peran serta orang tua yang berasal dari guru yang telah berpengalaman atau anggota sekolah dari tim manajemen.

Dari temuan tentang bentuk-bentuk partisipasi di atas, peneliti menyimpulkan adanya beragam bentuk keterlibatan orang tua dimana orang tua dapat memilih berdasarkan minat dan bakatnya. Bentuk-bentuk peran serta orang tua yang ada di Sekolah PSKD Mandiri antara lain adalah Leadership Day (Hari Kepemimpinan), Need For Dash (Lomba Lari dan Mengumpulkan Dana), Parents Visit (Kunjungan Orang tua di kelas), Teacher Appreciation Day (Hari Penghargaan bagi Guru dan Staff), Bulan Bahasa, Kompetisi Olahraga, Year End Performance (Pertunjukan Akhir Tahun), Community Service (Pelayanan kepada Masyarakat), Memasak di kelas, bazar sekolah, Trash for Cash (Bank Sampah), Program Membaca, Coffee Morning (Kegiatan berdiskusi dan bertanya kepada Sekolah), seminar orang tua dan lain-lain. Orang tua juga tidak serta merta memberikan dana berupa uang tapi ada kreatifitas dan nilai dalam setiap program yang diusulkan. Ada nilai pendidikannya yang dikembangkan sesuai dengan visi sekolah, seperti program Trash For Cash yang melatih kesadaran lingkungan.

Kendati demikian sekolah masih perlu fokus dalam mengembangkan aspek ketika bekerja sama dengan orang tua, seperti misalnya aspek pendidikan bagi orang tua. Sekolah perlu mengembangkan kerjasama bagi anak berkebutuhan khusus. Anak berkebutuhan khusus memiliki KPI-nya yang disesuaikan di setiap jenjang dengan kemampuannya. Nah karena kekhususannya itu orang tua dan guru perlu bekerjasama yang tentu berbeda pula dengan orang tua pada umumnya. Biasanya guru 
menyampaikan perkembangannya kepada orang tua. Orangtua juga perlu mendampingi atau ada tindakan khusus yang dilakukan di rumah.

Orang tua dalam organisasi PTSG (Parents Teacher Support Group) juga merasa bukan sebagai mesin penghasil uang dalam mendukung proses belajar mengajar di sekolah. Sehingga peranan orang tuanya juga tumbuh dari pengertian dan kepercayaan bahwa peranan mereka dibutuhkan dalam meningkatkan mutu sekolah.

\section{PENUTUP}

Kesimpulan: Berdasarkan hasil temuan dan pembahasan temuan penelitian, dapat disimpulkan bahwa: (1) Proses komunikasi interpersonal di SD PSKD Mandiri berlangsung cukup efektif. Prosedur pengaduan atau ketika orang tua melakukan kontak dengan guru d lakukan secara bertahap dan terstruktur. Sekolah memfasilitasi dengan memberikan ruangan khusus bagi orang tua. Meskipun tak dipungkiri bahwa sesekali terdapat tantangan dalam komunikasi interpersonal namun ada upaya-upaya perbaikan dalam mengatasi hal tersebut. Pimpinan mendorong komunikasi interpersonal yang baik antara rumah dan sekolah. Orang tua, sekolah, dan yayasan memandang bahwa komunikasi interpersonal yang efektif antara guru - orang tua atau sekolah - rumah sangat penting dalam sistem budaya mutu di SD PSKD Mandiri. (2) Saluran komunikasi di SD PSKD Mandiri sangat beragam. Orang tua bebas memilih saluran komunikasi yang diinginkan. Ada banyak cara untuk melakukan kontak seperti melalui perjanjian (appointments), sesi info (info session), surat sekolah (newsletter), pembagian rapor (parent/teacher Interview), buku penghubung (student diaries), Bbm (sms blast), e-mail dan lain sebagainya. SD PSKD Mandiri menerapkan teknologi, inovasi dan kreatifitas dalam mengembangkan saluran komunikasinya kepada orang tua. Penggunaan website sekolah berkembang semakin baik dan mendapat respon positif dari orang tua. Informasi disampaikan secara berkala sehingga orang tua memahami apa yang terjadi di dalam kelas. SD PSKD Mandiri melakukan survey kepada orang tua tentang peranan orang tua secara berkala dan menyediakan tempat bagi kritikan atau masukan bagi sekolah dalam websitenya. Kendati demikian prosentase peningkatan orang tua yang melihat website perlu ditingkatkan. 3) SD PSKD Mandiri memiliki kebijakan tertulis tentang peranan orang tua dalam buku aturan sekolah (handsbook). Kebijakan itu memuat pula aspek-aspek dimana sajakah orang tua dapat terlibat. Selain itu, SD PSKD Mandiri juga memiliki kebijakan tertulis tentang peran komite orang tua yang dinamakan PTSG (Parents Teacher Support Group). Kebijakan ini dinamakan konstitusi. Konstitusi ini dibuat oleh orang tua dan sekolah. Konstitusi didisain agar komite orang tua memiliki kerangka kerja yang jelas (4) Partisipasi orang tua yang ada di SD PSKD Mandiri sangat beragam. Sekolah mendorong orang tua untuk memilih peran berdasarkan minat dan bakatnya. Beragam aktifitas orang tua dilakukan berdasarkan analisa kebutuhan pendidikan yang diketahui dari hasil audit, supervisi pembelajaran, maupun keluhan pelanggan. Orang tua dilibatkan dalam perencanaan dan jenis aktifitas yang akan dilakukan. Bentuk-bentuk peran serta orang tua berupa keterlibatan orang tua di rumah dan sekolah. (5) Komite sekolah, PTSG (Parents Teachers Support Group) sangat aktif peranannya dalam mendukung sekolah. Komite orang tua ini berkontribusi dalam memberikan ide atau kegiatan kepada sekolah. Peranan orang tua di SD PSKD Mandiri tumbuh dari pengertian dan kepercayaan bahwa orang tua bukan sebagai mesin pencari dana atau money machine melainkan karena peranannya memang dibutuhkan dalam mendukung sekolah. (6) Proses perbaikan berkelanjutan dilakukan dengan menimbang masukan orang tua baik secara langsung maupun melalui survey secara berkala. Sekolah melakukan survey untuk meminta pendapat 
orang tua bagi perbaikan mutu sekolah. Selain itu SD PSKD Mandiri juga mulai menerapkan Parents Engagement System dalam strateginya. Melalui sistem ini diharapkan orang tua lebih terlibat aktif dalam mendukung sekolah dan prosentase jumlah kehadiran orang tua dapat ditingkatkan. (6) PSKD Mandiri mengangkat seorang koordinator orang tua. Walaupun pengaruh keterlibatan orang tua terhadap kesuksesan siswa sangat besar, tidak dipungkiri bahwa pekerjaan ini juga membutuhkan waktu dan tenaga. Dalam hal ini koordinator orang tua memastikan sistem peran serta orang tua berada pada jalur yang tepat.

Saran: Beberapa hal yang disarankan dalam penelitian ini adalah sebagai berikut: (1) Memberikan pelatihan bagi guru bagaimana berkomunikasi efektif dengan orang tua. Selama ini materi pelatihan atau training bagi guru lebih ditekankan pada aspek pembelajaran/ pengajaran. Program pelatihan guru ini dapat memberikan training tentang keterampilan mendengarkan efektif, teknik melakukan permintaan dan menolak permintaan, memberikan masukan yang membangun, mengelola kritik dari orang tua dan sebagainya. Guru juga perlu mendapatkan pengetahuan bagaimana caracara strategis untuk bekerjasama dengan orang tua dari latar belakang yang berbeda, seperti budaya dan bahasa. (2) Memberikan pemahaman melalui seminar-seminar kepada orang tua tentang pentingnya peranan mereka dalam proses pendidikan putraputrinya. Orang tua memerlukan pengetahuan dan pemahaman dalam mendampingi pendidikan putra-putrinya agar anaknya kelak mampu mencapai potensi terbaiknya. (3) Mengevaluasi program yang sudah berjalan dalam upaya terus mendorong peran serta orang tua yang berkelanjutan. (4) Mempertahankan peran koordinator orang tua yang cukup efektif dalam memastikan sistem peran serta orang tua berada pada jalur yang tepat. (5) Kendati memiliki perhatian kepada anak berkebutuhan khusus, SD PSKD perlu melakukan kerjasama yang lebih serius dengan orang tua yang memiliki anak berkebutuhan khusus ini. Sama halnya dengan anak berkebutuhan khusus, orang tua yang memiliki anak berkebutuhan khusus memiliki kekhususan pula. Hal-hal yang dibutuhkan atau yang dapat mereka kontribusikan ke sekolah mungkin berbeda dengan orang tua lain pada umumnya. Orang tua yang memiliki anak berkebutuhan khusus perlu bekerjasama dengan sekolah misalnya terlibat dalam IEP mereka. Orang tua perlu terlibat dalam memahami kelemahan dan kekuatan anaknya. Selain itu mereka dapat pula mendiskusikan tujuan pembelajaran dan apa yang menjadi prioritas bagi anaknya.

\section{DAFTAR RUJUKAN}

Epstein, J.L. School, Family, Community Patnership: Caring for The Children We Care Promising Practices for Family Involvement in School. Phi Delta Kappan. 1995. Vol 76.

Epstein, J.L., \& Salinas, K. C. Patnering with Families And Communities. Educational Leadership. 2013. Vol 6/(8).

Grant, K. B. \& Ray, J.A. Home, School and Community Collaboration: Culturally Responsive Family Involvement. Los Angeles: Sage, 2010.

Goetsch, David L. dan Davis, Stanley, Quality Management for Organizational Excellent: Introduction to Total Quality. New Jersey: Pearson, 2013. 
Hardjosoedarmo S., Total Quality Management. Yogyakarta: Andi, 2004.

Hornby, Garry, Parental Involvement in Children Education: Building Effective School FamilyPartnership. New York: Springer Media, 2011.

Hover-Dempsey et all., Why Do Parents Become Involved? Elementary School Journal, 106 (2), 2005.

Jenes, William H., A Meta Analysis of The Relation of Parental Involvement to Urban Elementary School Student Academic Achievement. Stanford NC: Collin Press Inc., 2005.

Ngaliman Purwanto, Administrasi dan Supervisi Pendidikan. Bandung: PT Remaja Rosdakarya, 2003.

Kudjo Donkor, Anthony, Ed.D., Changing the Context of Learning for a Better Education. Journal of Education and Practice, Vol.4, 2013.

Watson, M. A., Gryna, F. M.Quality Culture in Small Business: Four Case Studies Quality Progress, Vol. 34 (1), 2001.

Parent Educators Empowering Parents in Schools, A Resource to Assist Parent Educators, Implement Effective Parental Involvement Strategies. Arizona: Mesa Public School For Parents, 2010-2011.

Pierce, Jon L.dan Gerdner, Donald G., Management and Behavior: An Integrated Perspective. South Western: Tomson Learning, 2002.

Ramirez, A. Y., Parental Involvement is Like Apple Pie: A Look at Parental Involvement in Two States. The High School Journal Vol 85 (1), 2001.

Robbins, Stephen P., Organitational Behavior terjemahan Benyamin Molan . Jakarta: Gramedia, 2006. 